\title{
Gender Equity and Athletics: Governing Legal Standards and Practical Applications
}

\author{
Ellen J. Vargyas \\ National Women's Law Center \\ Washington, D.C.
}

\section{INTRODUCTION}

Gender discrimination in education-related athletics is a pervasive and endemic problem - at both the secondary and post-secondary levels. More than anything else, it defines the athletic experience of the more than half of the students nationwide who are not male. Moreover, because of the laws prohibiting such discrimination and because of expanding remedies, it also goes directly to the legal status and liability of education institutions across the country.

\section{THE FACTS}

Before writing in more detail about the law, let me quickly review the scope of the problem. And it is a large problem - make no mistake.

\section{Participation}

Although over half of the secondary and post-secondary population is female, under a third of college athletes overall are female. Indeed, recent NCAA statistics (Raiborn, "Revenues and Expenses of Intercollegiate Athletics Programs") seem to suggest that the percentage, which held constant for over ten years, may be dropping. These show that for 1989 only $28 \%$ of Division I-A athletes, for example, are female. The highest percentage of women athletes is found at Division III schools which don't offer football, and there the percentage is only $44 \%$. Only slightly more - at about $35 \%$ - of high school athletes are female.

While there are a number of reasons for this enormous discrepancy between female enrollment and female participation in athletics, perhaps the most significant explanation results from high school and college decisions regarding which sports they will offer to their students. At the high school level the explanation for the disparity is abundantly clear: schools offer approximately twenty five thousand fewer teams nationwide to girls than to boys. This does not even take into account the fact that football offers substantially more participation opportunities to boys than does any girls' sport. As a result, even if girls and boys are offered the same number of teams, if one of those teams is football, boys will have significantly more 
participation opportunities than will girls. On the college level, the number of team offerings by gender is closer although it also tilts toward males. The Raiborn study shows that all NCAA divisions except Division II and III schools which don't offer football offer more sports to male athletes than to their female athletes. In these two categories, the average number of sports offered are the same. Nowhere are young women offered more sports than their brothers. However again, given the size of football teams, even equity in the number of sports will result in the two to one participation ratio which has long characterized education-related competitive athletics. In any event, the number of sports is ultimately irrelevant. Sports (or teams) do not have legal rights; students do.

\section{Operating Expenditures}

Aside from participation, operating support to female teams is substantially less than that offered to male teams. It is also substantially less than would be warranted even by their depressed participation rates. The Raiborn analysis shows that for 1989 , in Division I-A teams, fully $82 \%$ of operating expenditures go to men. The numbers in other NCAA divisions are slightly better but still far short of anything resembling equity. It is also informative to look at the breakdown by categories of expenditures. For example, in Division I-A, women get only $21 \%$ of team travel dollars. This is in spite of the fact that bus and airplane seats cost the same regardless of who's sitting in them. Clearly, women are traveling less than male athletes and in less style. In other categories women get only $19 \%$ of salary expenditures and $16 \%$ of equipment dollars.

\section{Scholarships}

The Raiborn study also shows - and this includes 1989 figures - that across NCAA divisions women receive a lower percentage of scholarships than even their depressed participation figures would warrant.

\section{Coaches}

The NCAA study shows that at every NCAA division, there are proportionately more coaches for men's programs than for women's, generally far-outstripping the difference in the number of teams offered.

\section{Employment}

Problems are not only faced by athletes. There are very serious problems encountered by women who seek employment in the area of education- related athletics. Carpenter and Acosta have found that:

1. While in 1972 women were over $90 \%$ of all coaches for women's teams, by 1988 they were less than half. Unchanged was the fact that in both years, less than $1 \%$ of coaches of men's teams were women.

2. The situation in sports administration is even worse. In 1972 , over $90 \%$ of women's programs were run by women. By 1988 that figure dropped to $16 \%$. Moreover by 1988 , only $29 \%$ of all administrative jobs in women's programs were held by women and no women at all were involved in the administration of $32 \%$ of women's programs.

3. Again, the administrators of men's programs were and are overwhelmingly 
male. (Less than $1 \%$ of men's programs, for example, have ever been run by women.)

\section{THE LAW}

This extraordinary evidence of discrimination notwithstanding, there are laws prohibiting discrimination on the basis of gender in education- related athletics. These include Title IX, the principal federal statute prohibiting sex discrimination in education, and the fourteenth amendment of the U.S. constitution which applies to public institutions. Also relevant are numerous state constitutional and statutory requirements. I will focus on the federal law but school counsel and other interested persons would be well- advised to acquaint themselves with state requirements. Before getting into the detail of the federal law, two issues should be quickly referenced. First, questions are raised regarding the meaning of equity in athletics where team integration is not necessarily the goal and male and female programs will often include different teams and different priorities. While these may ultimately be difficult and complex questions they are not terribly relevant to the question at hand. For the current situation is so grossly inequitable that we are far away from the luxury of debating the fine points of the precise meaning of gender equity in athletics. Second is the place of football. Contrary to what some seem to suggest as they argue that somehow football should be taken out of a gender-equity analysis, football is most assuredly a men's sport. There is no legal - let alone empirical - support for any other proposition.

\section{Title IX Generally}

1. With the passage of the Civil Rights Restoration Act in 1988, over President Reagan's veto, Congress left no question regarding Title IX's coverage. It applies institution-wide to all education institutions which receive any federal funds, including student aid. This includes the vast majority of secondary and post-secondary schools across the country.

2. Title IX may be enforced administratively through the Department of Education's Office for Civil Rights as well as judicially through a private right of action without an exhaustion requirement.

3. Prevailing plaintiffs in Title IX litigation are entitled to attorneys' fees from defendants. Such awards can be very substantial, running well into six figures, if not higher.

4. In addition, the U.S. Court of Appeals for the Third Circuit recently ruled in Pfeiffer v. Marion Center Area School District that compensatory damages are available under Title IX in cases of intentional discrimination. Because there are nearly always facial gender-based classifications in athletics cases, intent is presumed. While the Eleventh Circuit reached a contrary result in Franklin v. Gwinnett County Schools (cert petition pending) where it held that damages are not available under Title IX, schools nonetheless face a very serious potential liability.

5. Finally, there is reason to believe that OCR will be improving on its rather dismal enforcement record of the last decade. Michael Williams, the Assistant Secretary for Civil Rights, has designated athletics as a 1991 priority. We have been working with OCR to assure that the investigators 
manual issued shortly prior to his confirmation will be revised to better reflect the requirements of the law. In addition, several major complaints are under investigation, most notably one regarding Brooklyn College.

\section{Title IX: Specifics}

\section{Participation}

The Title IX standard is "whether the selection of sports and levels of competition effectively accommodate the interests and abilities of members of both sexes." Under the regulations, separate teams by gender are permitted where selection is based upon competitive skill or in contact sports (boxing, wrestling, rugby, ice hockey, football, basketball, etc.) The Policy Interpretation sets standards for when particular sports must be offered. For contact sports, if a team is offered to members of one sex it must be offered to the other if: (1) members of the excluded sex have historically had limited opportunities and (2) there is a reasonable likelihood that a team of qualified athletes could be fielded and compete. It is the Policy Interpretation requirement regarding selection of sports that most likely recently led the University of Oklahoma and William and Mary College to rescind plans to cut their women's basketball teams. For non-contact sports the same requirements apply with the addition that a separate team is required unless members of the excluded sex have an opportunity to try out for the single team and an opportunity to compete meaningfully on it. In addition to these sport selection questions, the baseline problem of inequitable participation offerings remains. Serious questions are presented by the refusal of many schools to implement new teams for girls and young women even though they have only half the participation opportunities of their male classmates.

2. Scholarships

The basic Title IX principle is that the female share of the scholarships must be proportional to their participation rate. The court in Haffer $v$. Temple University held that a school can't rely on discriminatorily reduced participation to justify discrimination in scholarships. There is an ongoing dispute over the proper measure of proportionality. Some argue that the appropriate analysis should be based on statistical significance. I think that the better view is that a statistically based analysis is inappropriate. Because we know the number of athletes and the number of scholarship dollars, a straight numerical comparison will better serve the purpose of the statute. There has been some suggestion that $\mathrm{OCR}$ is moving to this position.

3. Other categories of comparison are included in the Title IX regulations. They include

1.provision of equipment and supplies

2. scheduling of games and practice time

3. travel and per diem allowance

4. opportunity to receive coaching and academic tutoring

5. assignment and compensation of coaches and tutors

6. provision of locker rooms, practice and competitive facilities

7. provision of medical and training facilities and services

8. provision of housing and dining facilities and services 
9. publicity

While the regulations do not impose a requirement of per capita equity in spending, expenditure levels are still highly probative of the question of compliance.

\section{Federal Constitution}

Constitutional litigation has focused primarily on participation questions at the secondary level: girls trying to get onto boys teams and boys trying to get onto girls teams. The test which is applied to claims of gender discrimination is known as midlevel or heightened scrutiny. Under this standard, to survive, a classification must bear a substantial relationship to an important governmental interest. The important governmental interest in these cases is generally identified as enhancing female participation. As it has been applied, girls tend to succeed and boys tend not to. In my view, this is the appropriate result.

\section{PRACTICAL APPLICATIONS}

It is clear that there is widespread non-compliance with the law prohibiting gender discrimination in athletics. Schools have two basic choices. First, they can restructure their programs in accordance with the law. Or, they can stay the current course which is to bet that the impediments to litigation will continue effectively to bar judicial intervention and that OCR will continue to fail to function in a meaningful fashion.

I wouldn't take the risk inherent in the second approach and I certainly wouldn't counsel any school to do so. There is a great deal of discontent and anger fermenting among girls and women at all levels of athletics. Increased action is certain to follow. Moreover, the introduction of a damages remedy certainly changes any risk assessment, particularly when added to existing attorneys fees remedies. Finally, there are signs that OCR is awakening from its enforcement stupor of the 1980's: action on the Brooklyn College complaint will be telling as will decisions regarding changes to the investigators manual, additional investigations and so forth.

Coming into compliance with the law, while perhaps painful to certain vested interests, is a fairly straightforward matter. Schools should:

1. Carefully evaluate selection of sports, including offerings of feeder institutions, Y's, country clubs, and other athletic programs.

2. Look at club and intramural sports within the institution to see where interest already exists.

3. Survey the student body regarding interest (an old Title IX requirement observed principally in the breach but extremely useful)

4. Use recruiting and marketing devices already in full force in connection with the typical men's program to build interest in and support for increased offerings by the women's program.

5. Add participation opportunities for female athletes.

6. Assure that scholarship expenditures are absolutely proportional: there is absolutely no excuse for anything else.

7. Start spending money fairly. There is no requirement or interest in requiring that women's athletic programs become mirror images of men's programs. Accordingly, women's programs may choose to spend resources in different 
ways than the model provided by the men's program. They may choose to spend more on publicity because they have a greater need to develop spectator interest or they may choose to spend more on travel if they have to go further to meet appropriate competition. Equity in particular categories is not the goal. What is key is that male and female athletes have access, overall, to the same resources. Anything less is a violation of the law.

The challenge to stop a pervasive and pernicious form of discrimination is squarely before us. The only question is whether America's high schools and colleges will have the courage to do the right thing. 